\title{
SELECTION OF THE TECHNOLOGICAL LINE STRUCTURE FOR THE BUILDING AGGREGATES PRODUCTION USING CENTRIFUGAL IMPACT CRUSHERS
}

\author{
Mikhail Ryabchikov ${ }^{1}$, Ruslan Burnashev ${ }^{2}$ \\ 1,2 Nosov Magnitogorsk State Technical University \\ Lenin Street, 38, Magnitogorsk, Russia \\ ${ }^{1} \mathrm{mr}$ _mgn@mail.ru
}

\section{Abstract}

The paper considers the problem of the organization of the technological line for the production of building aggregates with a given particle size distribution. The advantage of two-stage crushing schemes is shown, which makes it possible to ensure a change in the ratio of large aggregate fractions within fairly wide limits.

The experience of using centrifugal-impact crushers for the operation of the production of CJSC Ural-Omega at the final stage of crushing is summarized. It was demonstrated that the use of two centrifugal impact crushers at the final stage of crushing allows to obtain mixtures of significantly different types. A method for selecting the option of organizing the process line and crushing parameters is proposed.

\section{Keywords}

Crushing and grading complex, centrifugal crushers, particle-size distribution of structural filling aggregates.

\section{Introduction}

The designing of concrete and asphalt-and-concrete mixes constitutes a challenging scientific and engineering task, since the results of solving it determine the qualitative indicators and cost of the final product.

The quality of filling aggregates as well as the particle-size distribution thereof plays an important role in designing and production of concretes. Therefore, a competent selection of sand content in the mix of filling aggregates (ratio of sand weight to the sum of weights of sand and crushed stone) providing the maximum concrete mix placeability with minimum binder consumption, is an essential part of designing concrete.

The value of sand content can be expressed as a function of cement paste, for which purpose a corresponding graph (Figure 1) will be provided during work (Sukhodoeva, Babitsky, 2009). This graph shows that the increase of sand content in the mix of filling aggregates will bring about an increase of concrete mix plasticity with the same of cement paste volume. Thus, we can make a conclusion that the particle-size distribution

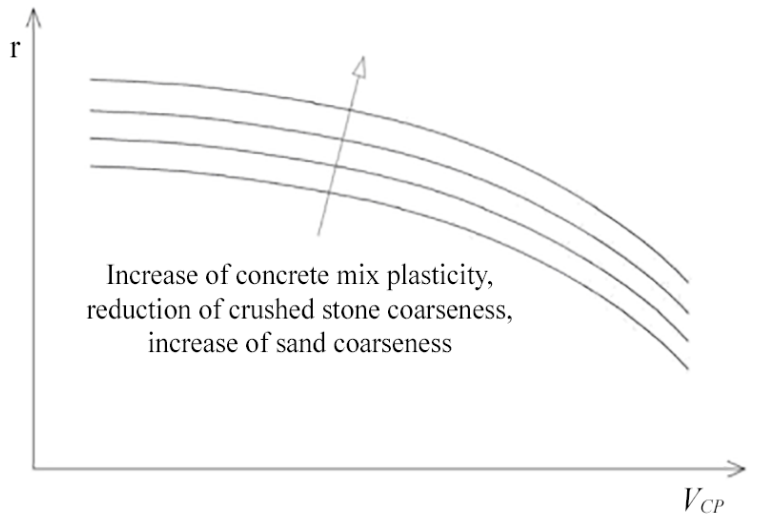

Figure 1. Sand Content in Filling Aggregates Mix $r$ vs Cement Paste Volume $V_{C P}$.

of filling aggregates directly influences the concrete mix plasticity and placeability.

In order to provide the required parameters of filling aggregates, it is necessary to determine correctly the structure and mode of operation of process equipment 
a)

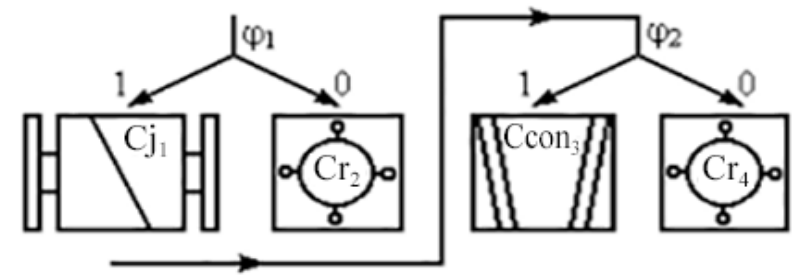

b)

\begin{tabular}{|c|c|c|c|c|c|c|c|c|c|c|c|}
\hline \multirow{2}{*}{$\begin{array}{l}\text { Card } \\
\text { Nos }\end{array}$} & \multirow{2}{*}{$\begin{array}{l}\text { Point } \\
\text { Nos }\end{array}$} & \multicolumn{4}{|c|}{ Control actions } & \multirow{2}{*}{$\begin{array}{l}\text { Card } \\
\text { Nos }\end{array}$} & \multirow{2}{*}{$\begin{array}{l}\text { Point } \\
\text { Nos }\end{array}$} & \multicolumn{4}{|c|}{ Control actions } \\
\hline & & $\varphi_{1}$ & $S_{\mathrm{J} 1} ; V_{\mathrm{R} 2}$ & $S_{\mathrm{C} 3} ; V_{\mathrm{R} 4}$ & $\varphi_{2}$ & & & $\varphi_{1}$ & $S_{\mathrm{J} 1} ; V_{\mathrm{R} 2}$ & $S_{\mathrm{C} 3} ; V_{\mathrm{R} 4}$ & $\varphi_{2}$ \\
\hline \multirow{2}{*}{1} & 1 & 1 & $S_{\mathrm{J} 1}=40$ & $S_{\mathrm{C} 3}=15$ & \multirow[t]{2}{*}{10} & \multirow{2}{*}{5} & 9 & 1 & $S_{\mathrm{J} 1}=40$ & $V_{\mathrm{R} 4}=45$ & \multirow{2}{*}{0} \\
\hline & 2 & 0 & $V_{\mathrm{R} 2}=45$ & $S_{\mathrm{C} 3}=15$ & & & 10 & 0 & $V_{\mathrm{R} 2}=45$ & $V_{\mathrm{R} 4}=45$ & \\
\hline \multirow{2}{*}{2} & 3 & 1 & $S_{\mathrm{J} 1}=100$ & $S_{\mathrm{C} 3}=15$ & \multirow{2}{*}{1} & \multirow{2}{*}{6} & 11 & 1 & $S_{\mathrm{J} 1}=100$ & $V_{\mathrm{R} 4}=45$ & \multirow{2}{*}{0} \\
\hline & 4 & 0 & $V_{\mathrm{R} 2}=20$ & $S_{\mathrm{C} 3}=15$ & & & 12 & 0 & $V_{\mathrm{R} 2}=20$ & $V_{\mathrm{R} 4}=45$ & \\
\hline \multirow{2}{*}{3} & 5 & 1 & $S_{\mathrm{J} 1}=40$ & $S_{\mathrm{C} 3}=50$ & \multirow{2}{*}{1} & \multirow[t]{2}{*}{7} & 13 & 1 & $S_{\mathrm{J} 1}=40$ & $V_{\mathrm{R} 4}=20$ & \multirow{2}{*}{0} \\
\hline & 6 & 0 & $V_{\mathrm{R} 2}=45$ & $S_{\mathrm{C} 3}=50$ & & & 14 & 0 & $V_{\mathrm{R} 2}=45$ & $V_{\mathrm{R} 4}=20$ & \\
\hline \multirow{2}{*}{4} & 7 & 1 & $S_{\mathrm{J} 1}=100$ & $S_{\mathrm{C} 3}=50$ & \multirow{2}{*}{1} & \multirow{2}{*}{8} & 15 & 1 & $S_{\mathrm{J} 1}=100$ & $V_{\mathrm{R} 4}=20$ & \multirow{2}{*}{0} \\
\hline & 8 & 0 & $V_{\mathrm{R} 2}=20$ & $S_{\mathrm{C} 3}=50$ & & & 16 & 0 & $V_{\mathrm{R} 2}=20$ & $V_{\mathrm{R} 4}=20$ & \\
\hline
\end{tabular}

Figure 2. Two-Stage Crushing Diagram with Application of Two Gate Bins: a) Layout of Crushers; b) Control Variants.
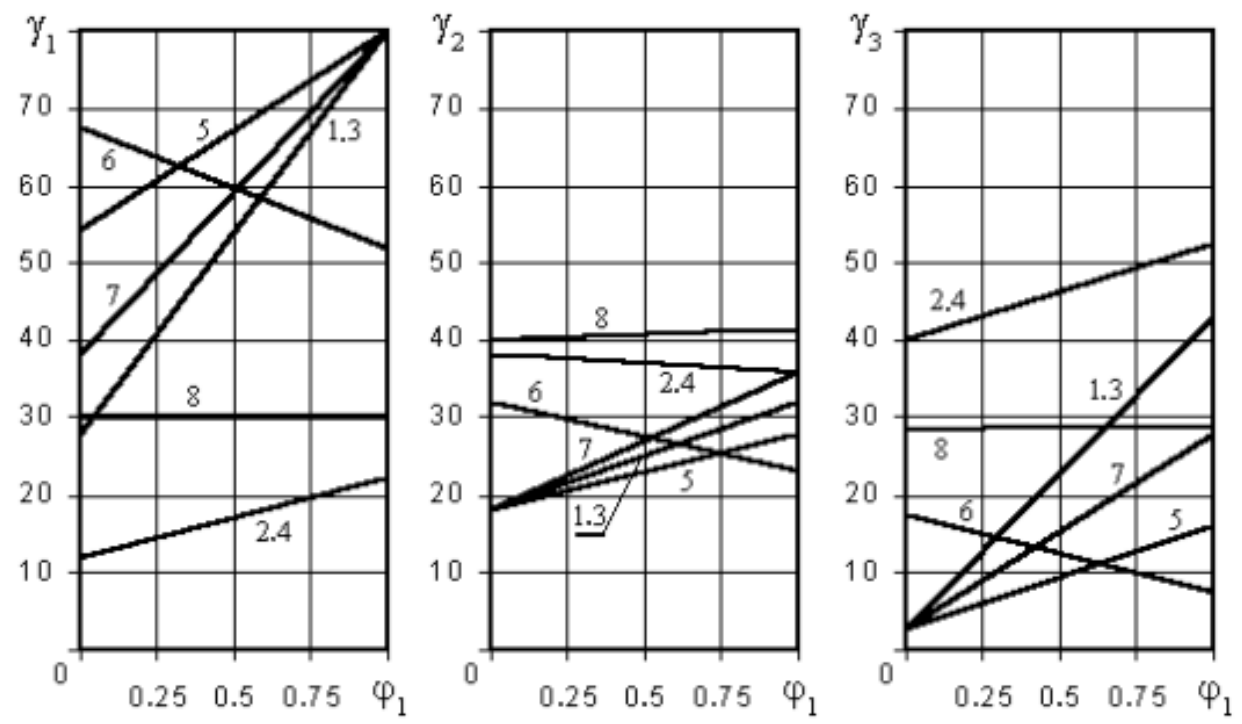

Figure 3. Output of Crushed Stone Fractions in Two-Stage Closed-Cycle Crushing Process.

of the production line. Some researchers pay special attention to the issues of determining an optimal structure of the production line (Gimadetdinov, Ostroukh, 2014; Ilyukhin et al., 2015; Suetina et al., 2009). For instance, a two-stage crushing diagram is offered during operation (llyukhin et al., 2015), where the crushers with different characteristics of grain-size distribution are used at both stages: jaw and rotor crusher - at the first stage, conical and rotor crusher - at the second stage.

The researchers have presented the results of experimental tests of a diagram with two primary crushers and one secondary one (points 1-8 of Table) in the form of the following graphs (Figure 3), where $\gamma_{1}, V_{2}, V_{3}$ correspond accordingly to fine, medium and coarse crushing products.

These graphs testify to the fact that in case of using a diagram of two-stage crushing and correct adjustment of crushing units under consideration it is possible to attain a change in the balance of fractions of coarse filling aggregates within rather wide limits. In this case a conical crusher is used as a secondary crushing unit (Shadrunova et al, 2015).

\section{Two-stage crushing scheme using centrifugal crushers}

According to the experience of development of the crushing and grading equipment of Ural-Omega CJSC and NPO Center the vertical-rotor centrifugal impact crushers (hereinafter referred to as the centrifugal crushers) feature a number of advantages when using these crushers as the units of the last crushing stage (Ural-Omega CJSC, 2016, Burnashev et al., 2015):

- Final product quality: high degree of reduction; stable particle-size distribution of final product; high quality indicators of crushed product, including content of grains of isometric (cubical) shape in the entire range of coarseness within the limits of $90 \%$. 


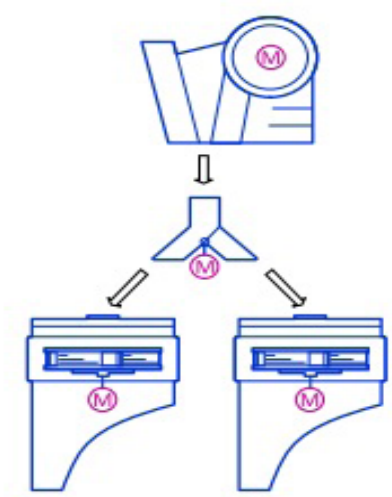

Figure 4. Two-Stage Crushing Diagram with the Use of Jaw Crusher and Two Centrifugal Crushers.

- Reliability: reduced wear of mechanical components due to lining with a crushable material; unbreakable inclusions, commensurate with the size of the power supply, do not lead to breakages and do not require stopping the work.

- Cost effectiveness: low operational costs; equipment utilization rate reaches 0.9 ; low power intensity; high reparability and ease of maintenance.

- Mobility: it does not require special foundations and can be installed on the aerodrome concrete slabs.

The particle-size distribution of the centrifugal crusher crushing products changes depending on the rotational speed of an accelerator adjustable by means of a frequency converter (Gazaleeva et al., 2019).
Thus, the following task can be worded: control of particle-size distribution of the two-stage crushing products with the use of two centrifugal crushers featuring different technical characteristics and/or adjustments at the second stage (Figure 4).

\section{Evaluation of the feasibility of using two centrifugal crushers according to the results of experiments}

In order to check the possibility of effecting such a control, the data of laboratory tests conducted at UralOmega CJSC have been analyzed. The test results have been selected for analysis, where the gravel size fraction of $5-20 \mathrm{~mm}$ has been crushed at centrifugal crushers DTs- 0.4 with self-lining of material being crushed and DTs0.36 with metal impact plate with different linear rotational speeds of the crusher accelerator $(\mathrm{V}, \mathrm{m} / \mathrm{s})$. The test data are shown in Tables 1-3:

Table 1. Yields by weight.

\begin{tabular}{|l|l|l|l|l|l|}
\hline \multirow{3}{*}{ Crusher type } & \multirow{2}{*}{$\mathrm{V}, \mathrm{m} / \mathrm{s}$} & \multicolumn{4}{|c|}{ Yields of fractions by weight, \% } \\
\cline { 3 - 6 } & & $\begin{array}{l}0-5 \\
\mathrm{~mm}\end{array}$ & $\begin{array}{l}5-10 \\
\mathrm{~mm}\end{array}$ & $\begin{array}{l}10-15 \\
\mathrm{~mm}\end{array}$ & $\begin{array}{l}10-15 \\
\mathrm{~mm}\end{array}$ \\
\hline \multirow{3}{*}{ DTs-0,4 } & 56 & 49.1 & 25.2 & 21.3 & 4.3 \\
\cline { 2 - 6 } & 65 & 53.9 & 25.9 & 16.8 & 3.4 \\
\cline { 2 - 6 } & 80 & 63.7 & 21.3 & 12.3 & 2.7 \\
\hline DTs-0,36 & 70 & 48.1 & 31.3 & 18.1 & 2.5 \\
\hline
\end{tabular}

Table 2. Sand grain compositions.

\begin{tabular}{|c|c|c|c|c|c|c|c|c|c|}
\hline \multirow{2}{*}{$\begin{array}{c}\text { Crusher } \\
\text { type }\end{array}$} & \multirow[t]{2}{*}{$\mathrm{V}, \mathrm{m} / \mathrm{s}$} & \multirow[t]{2}{*}{ Мк } & \multirow{2}{*}{$\begin{array}{l}\text { Sieve } \\
\text { residues }\end{array}$} & \multicolumn{6}{|c|}{ Sieve residue with mesh, $\mathrm{mm}, \%$} \\
\hline & & & & 2.5 & 1.25 & 0.63 & 0.315 & 0.16 & Bottom \\
\hline \multirow{6}{*}{ DTs-0.4 } & \multirow[t]{2}{*}{56} & \multirow[t]{2}{*}{3.54} & Individual & 43.2 & 20.3 & 11.5 & 8.0 & 6.1 & 10.9 \\
\hline & & & Full & 43.2 & 63.5 & 75.0 & 83.0 & 89.1 & 100.0 \\
\hline & \multirow[t]{2}{*}{65} & \multirow[t]{2}{*}{3.37} & Individual & 35.4 & 23.1 & 13.9 & 9.2 & 7.0 & 11.4 \\
\hline & & & Full & 35.4 & 58.5 & 72.4 & 81.6 & 88.6 & 100.0 \\
\hline & \multirow[t]{2}{*}{80} & \multirow[t]{2}{*}{3.09} & Individual & 26.0 & 25.7 & 15.3 & 10.8 & 8.4 & 13.8 \\
\hline & & & Full & 26.0 & 51.8 & 67.1 & 77.8 & 86.2 & 100.0 \\
\hline \multirow[t]{2}{*}{ DTs-0.36 } & \multirow[t]{2}{*}{70} & \multirow[t]{2}{*}{3.84} & Individual & 48.3 & 23.1 & 11.2 & 6.2 & 4.2 & 7.0 \\
\hline & & & Full & 48.3 & 71.4 & 82.6 & 88.8 & 93.0 & 100.0 \\
\hline
\end{tabular}

Table 3. Qualitative indicators of crushed stone made of gravel.

\begin{tabular}{|c|c|c|c|c|c|c|c|}
\hline Crusher type & $\mathrm{V}, \mathrm{m} / \mathrm{s}$ & $\begin{array}{l}\text { Size fraction, } \\
\mathrm{mm}\end{array}$ & $\begin{array}{c}\text { Content of } \\
\text { crushed } \\
\text { grains, \% }\end{array}$ & $\begin{array}{l}\text { Flakiness } \\
\text { index, \% }\end{array}$ & $\begin{array}{l}\text { Crushed } \\
\text { stone group }\end{array}$ & $\begin{array}{l}\text { Loss of } \\
\text { mass during } \\
\text { crushability } \\
\text { test, } \%\end{array}$ & $\begin{array}{l}\text { Grade with } \\
\text { respect to } \\
\text { crushability }\end{array}$ \\
\hline \multirow{6}{*}{ DTs-0.4 } & \multirow[t]{2}{*}{56} & $5-10$ & 52 & 5.2 & 1 & 2.5 & 1000 \\
\hline & & $10-15$ & 25 & 3.7 & 1 & 5.0 & 1000 \\
\hline & \multirow[t]{2}{*}{65} & $5-10$ & 67 & 3.4 & 1 & 2.6 & 1000 \\
\hline & & $10-15$ & 37 & 1.9 & 1 & 4.1 & 1000 \\
\hline & \multirow[t]{2}{*}{80} & $5-10$ & 71 & 1.8 & 1 & 2.1 & 1000 \\
\hline & & $10-15$ & 41 & 2.8 & 1 & 4.3 & 1000 \\
\hline \multirow[t]{2}{*}{ DTs-0.36 } & \multirow[t]{2}{*}{70} & $5-10$ & 73 & 12.0 & 2 & 2.9 & 1000 \\
\hline & & $10-15$ & 53 & 5.2 & 1 & 5.1 & 1000 \\
\hline
\end{tabular}


A

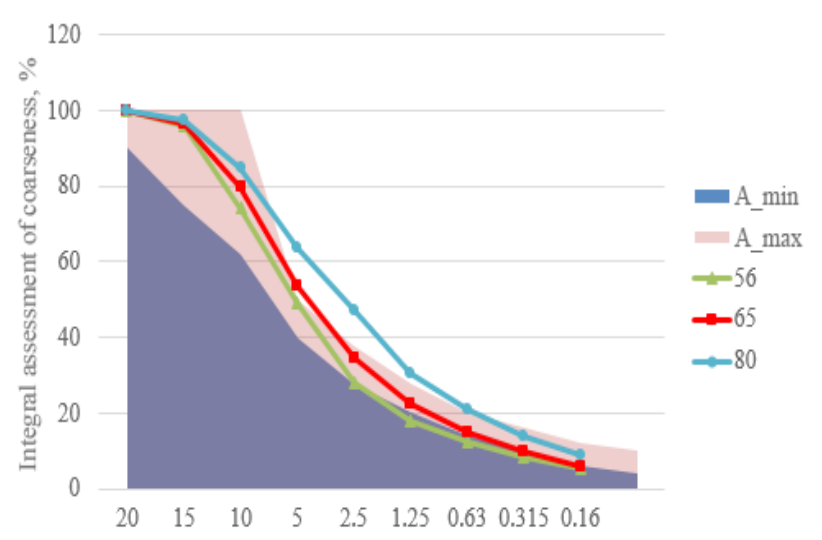

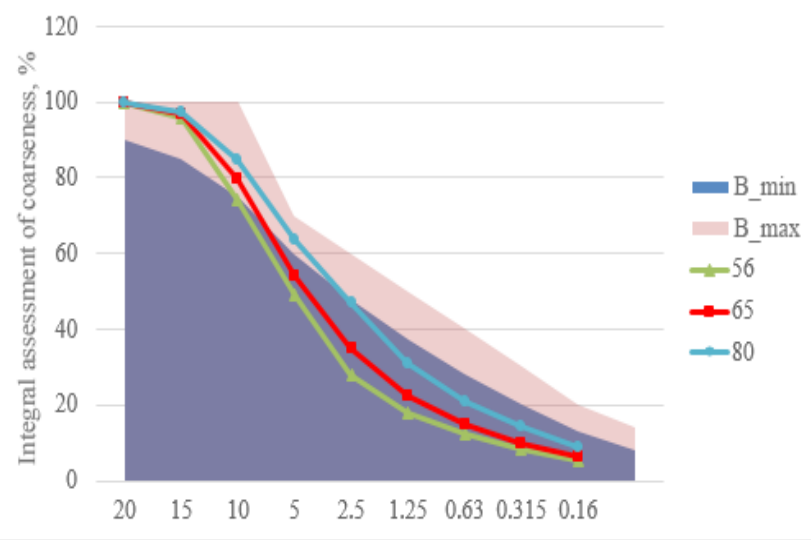

Figure 5. Integral Curves of Particle-Size Distribution for DTs-0.4 at Different Velocities Under Condition of Producing Filling Aggregates for Upper Layers of Asphalt Concrete pavement of A and B Types.

Let us give consideration to the test results in the context of producing the filling aggregates of the specified grainsize distribution for the upper layers of asphalt-concrete pavement according to GOST 9128-2013 (Federal center for rationing, standardization and technical conformity assessment in construction, 2013) (Figure 5).

The demonstrated data show that DTs-0.4 makes it possible that the required particle-size distribution of filling aggregates of medium size fractions $(5-20 \mathrm{~mm})$ for mixes of A type, the same as for the mixes of $B$ type, but the yield of fine size fractions $(0-5 \mathrm{~mm})$ is to be increased for B-type mixes. In this case it should be noted that the manufactured products correspond to the first class with respect to flakiness index, i.e. they feature high quality.

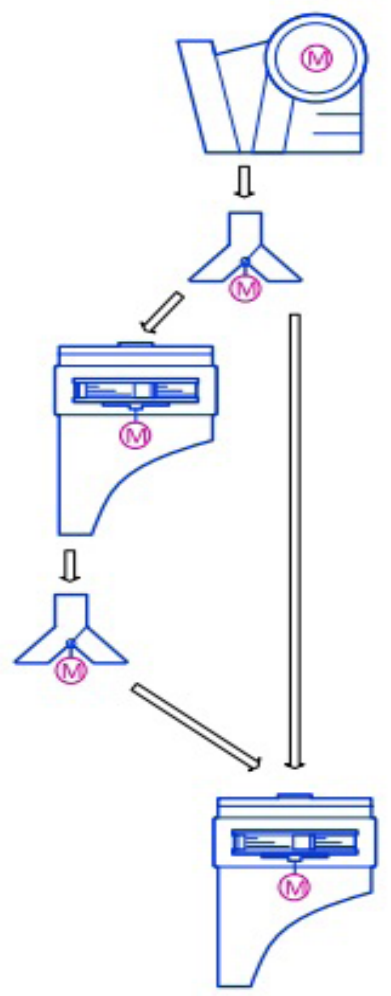

Figure 6. Two-Stage Crushing Diagram with the Use of Jaw Crusher and Two Centrifugal Crushers (Variant 2).
A similar analysis of the particle-size distribution of crushing products DTs- 0.4 for B-type filling aggregates has shown that it is possible to select a mode, where the specified indicators will be ensured (of the order of $70 \mathrm{~m} / \mathrm{s}$ ). In order to produce mixes of $D$ and $E$ types, where the size fractions of $10-20 \mathrm{~mm}$ are absent, it is necessary to carry out a repeated crushing. Thus, the following crushing diagram is considered to be more reasonable (Figure 6). This crushing diagram will help implement different modes providing production of the specified particle-size distribution.

If it is necessary to obtain mix of $A$ or $B$ type, the source material is to be fed from the jaw crusher to both centrifugal crushers, which must feature equal rotational speeds of an accelerator (50 or $70 \mathrm{~m} / \mathrm{s}$, accordingly). It is also possible to produce mixes of $A$ and $B$ type in a specified balance simultaneously in the way of controlling material feed from the jaw crusher by means of flows distributor.

If it is necessary to obtain mix of C, D and $E$ types, it is practical to get it by means by means of successive crushing, i.e. the material from the jaw crusher should be fed to one centrifugal crusher only. Apparently, it is possible to provide production of $\mathrm{C}$-type mix at low speeds of a rotor of both centrifugal crushers, and mixes of $D$ and E types - at high speeds.

The selection of the variant of the organization of the technological line and crushing parameters

Definitely, the particle-size distribution of crushing products depends on many factors, and an example being considered does not make it possible to guarantee production of all types of mixes using any material as well does not cover production of mixes, e.g., for the bed courses of asphalt concrete pavements (since the coarseness of feeding DTs- 0.4 shall not exceed $20 \mathrm{~mm}$ ).

In order to study the capabilities of the proposed crushing diagram, the additional experiments are required (Matveev et al., 2018).

However, the provided data demonstrate a possibility in principle to get the required particle-size distribution of 


\section{Architecture and Engineering Volume 4 Issue 1}

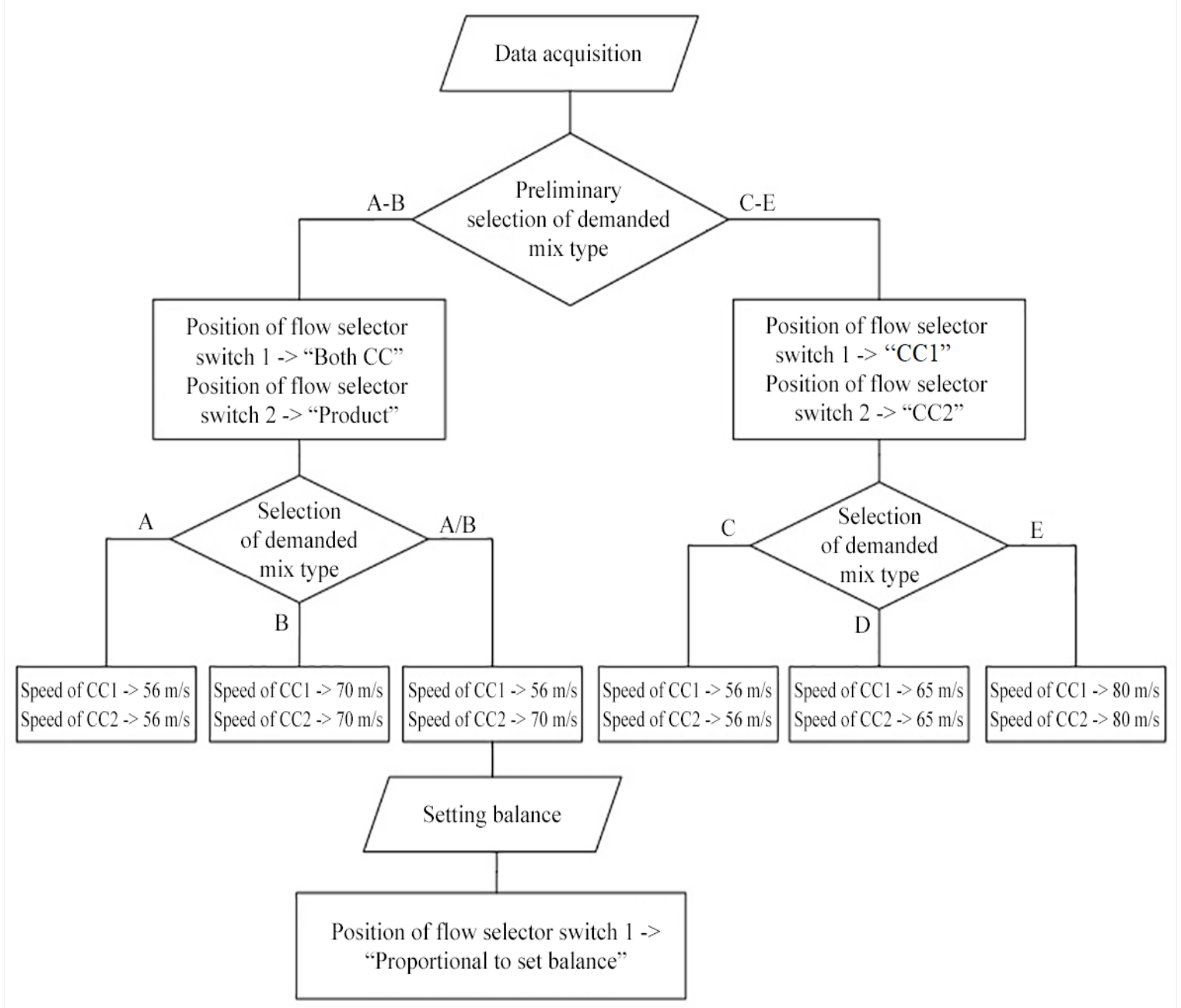

Figure 7. The block diagram of the selection of options for the organization and crushing parameters for the proposed technological scheme.

crushing products using the proposed method. Besides, the analysis of laboratory tests on crushing gravel and granite shows the similar results.

An important peculiarity is a fact that the crushing products correspond, as a rule, to the first class with respect to flakiness index.

Thus, one can articulate the following variant of algorithm of crushing process control according to the proposed diagram (Figure 7).

The demonstrated block diagram illustrates the control logic. Definitely, the speeds of accelerators of centrifugal crushers are to be selected according to data about the material, equipment, etc.

Apart from the process advantages an offered approach helps attain a number of operational advantages:

- Common hardware components of the units make it possible to keep a two-times smaller stock of fastwearing parts;

- Possibility of quick re-adjustment of centrifugal crusher operating mode will help not to stop one of the units during repair or preventive maintenance of the second unit.

- Identity of assemblies of the units simplifies the personnel training on operation and scheduled maintenance.
Thus, the offered method of production organization will help to increase the equipment reliability as a whole and reduce downtime as a result of emergencies and scheduled maintenance.

The analysis of statistical data with respect to crushing process in high-performance centrifugal crushers with the coarseness of feed up to $70 \mathrm{~mm}$ constitute the following task in this direction in order to prove serviceability of the proposed diagram at the production facility as well as implementation of the control system making it possible to effect the offered method. In case of using DTs-0.4 a task of designing a mobile line in the form of a unitized package seems to be relevant due to equipment portability and low power.

\section{Conclusion}

A method of crushing process organization has been offered making it possible to increase production qualitative and quantitative characteristics as well as its operational reliability, which is testified by the analysis of laboratory tests as well as by the general algorithm of process control when using this method.

The lines of scientific and engineering activity have been defined for the development of the offered control method. 


\section{References}

Burnashev R.E., Ryabchikov M.Yu., Grebennikova V.V., Ryabchikova E.S. (2015). The study of probable approaches to controlling the centrifugal-type crushers manufactured by Ural-Omega CJSC factoring in the product quality. Vestnik of Nosov Magnitogorsk State Technical University, № 1 (49), pp. 82-89.

Gazaleeva, G.I., Bulatov, K.V., Levchenko, E.N. (2019). The choosing special methods of disintegration for very complicated rare ore. In: Proceedings of 29th International Mineral Processing Congress, pp. 258-268.

Gimadetdinov, M.K., Ostroukh, A.V. (2014). Determining a List and Sequence of Solving Tasks of Automated Crushing and Grading Production. Automation and Control in Technical Systems, 4, pp. 55-61.

Federal center for rationing, standardization and technical conformity assessment in construction (2013). Asphalt-and-Concrete, Polymer Asphalt-and-Concrete Mixes, Asphalt Concrete, Polymer Asphalt-and-Concrete for Motor Roads and Airfields. GOST 9128-2013. Moscow: Federal center for rationing, standardization and technical conformity assessment in construction.

Ilyukhin, A.V., Marsov, V.I., Kolbasin, A.M., Tolmachev, A.G. (2015). Determining an Optimal Structure of Process of Two-Stage Crushing of Stone Materials at Coating Plants. MADI Bulletin, 3 (42), pp. 102-109.

Matveev, A., Lebedev, I., Lvov, E., Osipov, D., Gavriliev, D., Sleptsova, E. (2018). Possibility of implementation of dry technology of gold-bearing ores roughing: Case study of "gurbey" deposit. E3S Web of Conferences, 56, 03012. DOI: 10.1051/ e3sconf/20185603012.

Shadrunova, I.V., Gorlova, O.E., Kolodezhnaya, E.V., Kutlubaev, I.M. (2015). Metallurgical slag disintegration in centrifugal impact crushing machines. Journal of Mining Science, 51 (2), pp. 363-368. DOI: 10.1134/S1062739115020210.

Suetina, T.A., Nanazashvili, I.Kh., Zolotarev, S.Yu. (2009). Automated System of Two-Stage Crushing. Stroitelnye Nauki, 4, pp. 85-87.

Sukhodoeva, N.V., Babitsky, V.V. (2009). Methods of Designing Concrete Composition. Bulletin of the Byelorussian-Russian University, 2 (23), pp. 167-176.

Ural-Omega CJSC (2016). A Page Comprises Data About All Types of Equipment Supplied by this Company. Available at: http:// www.uralomega.ru/. (accessed on: 11.02.2019). 